\title{
PENGGUNAAN TEMBAGA SEBAGAI BAHAN CATALYTIC CONVERTER TERHADAP PERFORMA MESIN SEPEDA MOTOR SATRIA FU 150
}

\author{
Muhammad Zaki 1), Abdul Ghofur 2), Sigit Mujiarto ${ }^{3)}$ \\ 1), 2)Program Studi Teknik Mesin, Fakultas Teknik Universitas Lambung Mangkurat \\ JL. Akhmad Yani Km.36 Banjarbaru, Kalimantan Selatan,70714 \\ 3) Program Studi Teknik Otomotif, Politeknik Negeri Banjarmasin, \\ JL. Akhmad Yani Km. 36 Banjarbaru, Kalimantan selatan, 70714 \\ E-mail : muhammadzaki.unlam@gmail.com.
}

\begin{abstract}
Many motorcycles increased within past few years, the gas emmited from the motorclyce will be polluted the population. One of technology that can reduce the emmited gas is using catalytic converter on the muffler. Catalytic converter is a catalyst that can alter or accelerate a matter (chemical reaction) of a carbon monoxide into carbon dioxide. In this research will use two types of catalytic converter that is honey comb and a copper plate. From the test can be seen that the catalytic converter with a honey comb shape better in terms of engine performance than the catalytic converter shaped plate. Compared wihtout any catalytic converter, the highest percentage honey comb catalyst reduce the power within $0.12 \mathrm{HP}$, and torque increased to 0.04 $\mathrm{Nm}$. While the highest copper catalyst that reduce the power within $0.71 \mathrm{HP}$, and torque decreased to $0.2 \mathrm{Nm}$.
\end{abstract}

Key word : Catalytic converter, Catalyst, Engine performance.

\section{PENDAHULUAN}

Dari data Badan Pusat Statistik (BPS) perkembangan jumlah kendaraan selalu meningkat setiap tahunnya, pada tahun 2013 jumlah kendaraan di Indonesia sebanyak 104.118.969 unit dan jenis kendaraan yang paling banyak yaitu sepeda motor dengan 84.732 .652 unit. Dari data tersebut maka potensi yang paling besar dalam mengurangi jumlah polusi udara di Indonesia salah satunya dengan memodifikasi saluran gas buang sepeda motor menggunakan Catalytic converter.

Dari jumlah kendaraan di Indonesia, masih banyak terdapat kendaraan yang belum menggunakan sistem injeksi sehingga hasil pembakarannya masih banyak mengandung emisi yang mengakibatkan polusi udara. Dengan adanya Catalytic converter maka emisi yang disebabkan oleh pembakaran tidak sempurna dapat dikurangi sebelum keluar dari knalpot. Disamping itu performa mesin juga tetap harus diperhatikan dalam penambahan Catalytic converter, sehingga menghasilkan Catalytic converter yang mampu mengurangi emisi gas buang tanpa menurunkan performa mesin.

Berdasarkan cara, pemikiran dan penelitian sebelumnya, salah satu teknologi yang dapat digunakan untuk mereduksi emisi gas $\mathrm{CO}$ dan $\mathrm{HC}$ adalah dengan pemasangan Catalytic converter yang dipasang pada system saluran pembuangan emisi gas atau knalpot. Oleh sebab itu pada penelitian ini bertujuan untuk menguji katalis tembaga dengan variasi bentuk Catalytic converter. 
Didasarkan pada kenyataan diatas maka dilakukan penelitian skala laboratorium dengan Judul : "Penggunaan Catalytic converter Berbahan Tembaga Terhadap Emisi Gas Buang Dan Performa Mesin Sepeda Motor Suzuki Satria FU 150“ yang dirancang dengan memperhatikan aspek sederhana, efisien dan murah.

\section{TINJAUAN PUSTAKA}

\section{Emisi Gas Buang}

Emisi gas buang adalah sisa hasil pembakaran bahan bakar di dalam mesin pembakaran dalam, mesin pembakaran luar, mesin jet yang dikeliarkan melalui sistem pembuangan mesin. Sisa hasil pembakaran beerupa air (H2O), gas $\mathrm{CO}$ atau disebut juga karbon monoksida yang beracun, $\mathrm{CO} 2$ atau disebut juga karbon monoksida yang merupakan gas rumah kaca, NOx senyawa nitrogen oksida, HC berupa senyawa hidrat arang sebagai akibat ketidak sempurnaan proses pembakaran serta partikel lepas (Krisna, 2015).

Sejatinya emisi gas sangat bergantung pada perbandingan bahan bakar udara yang digunakan. Pada motor bensin yang konvensional dengan perbandingan bahan bakar udara yang kaya, kadar NOx dalam gas buang turun, akan tetapi kadar $\mathrm{CO}$ dan $\mathrm{HC}$ naik. Jika digunakan perbandingan bahan bakar udara yang miskin, kadar CO dan HC turun, tetapi kadar NOx naik. Sedangkan jika digunakan perbandingan campuran yang sangat miskin, kadar $\mathrm{CO}$ dan NOx turun, tetapi kadar HC bertambah besar. Hal tersebut disebabkan karena terjadinya kesulitan penyalaan, kecepatan pembakaran yang rendah serta pembakaran yang tidak stabil. (Arismunandar, 2005)

Berikut baku mutu emisi gas buang sumber bergerak kendaraan bermotor yang telah ditetapkan Per.MENLH no 05 tahun 2006.

Tabel 2.1 Baku mutu emisi gas buang kendaraan bermotor tipe L (Per.MENLH no 05 Tahun 2006)

\begin{tabular}{|l|c|c|c|c|}
\hline \multirow{2}{*}{\multicolumn{1}{|c|}{ Kategori }} & Tahun & \multicolumn{2}{c|}{ Parameter } & \multirow{2}{*}{ Metode Uji } \\
\cline { 3 - 4 } & pembuatan & $C 0(\%)$ & HC (ppm) & \\
\hline Sepeda Motor 2 tak & $<2010$ & 4,5 & 10.000 & Idle \\
Sepeda Motor 4 tak & $<2010$ & 5 & 2400 & Idle \\
Sepeda Motor (2 tak \& 4 tak) & $\geq 2010$ & 4,5 & 2000 & Idle \\
\hline
\end{tabular}


Ada empat sumber polusi yang berasal dari kendaraan bermotor, yaitu :

a. Pipa gas buang (knalpot) adalah sumber yang paling utama (65-85\%) dan mengeluarkan hidrokarbon (HC) yang terbakar maupun tidak terbakar, bermacam-macam nitrogen oksida (NOx), karbon monoksida (CO) dan campuran alkohol, aldehida, keton, penol, asam, ester, ether, epoksida, peroksida dan oksigen yang lain.

b. Bak oli adalah sumber kedua (20\%) dan mengeluarkan hidrokarbon yang terbakar maupun tidak yang dikarenakan blowby.

c. Tangki bahan bakar adalah faktor yang disebabkan oleh cuaca panas dengan kerugian penguapan hidrokarbon mentah $(5 \%)$.

d. Karburator adalah faktor lainnya, terutama saat berkendara pada posisi stop and go (kondisi macet) dengan cuaca panas, dengan kerugian penguapan dan bahan bakar mentah (5-10\%) (Warju, 2009)

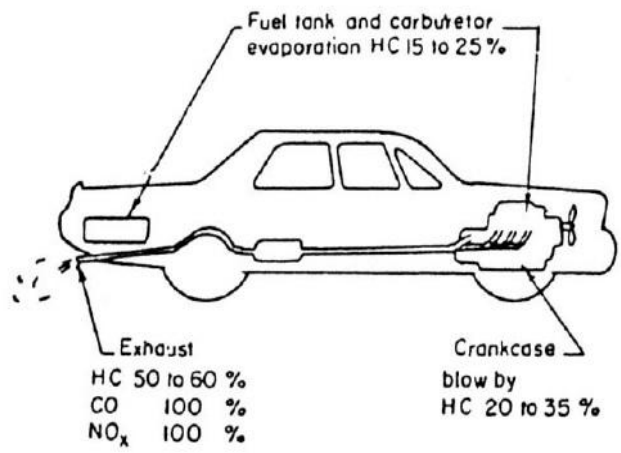

Gambar 1. Sumber Emisi Pada Kendaraan

(Sumber : Pradana, 2012)

\section{Catalytic converter}

Catalytic converter pada dasarnya merupakan sebuah reaktor unggun tetap (Fixed Bed Reaktor) yang beroperasi dinamis dan mengolah zat-zat yang mengandung emisi gasbuang berbahaya menjadi zat-zat yang tidak berbahaya. Catalytic converter merupakan sebuah converter (pengubah) yang menggunakan media yang bersifat katalis, dimana media tersebut diharapkan dapat membantu atau mempercepat terjadinya proses perubahan suatu zat (reaksi kimia) sehingga gas seperti CO dapat teroksidasi menjadi CO2 (Springer-Verlag. New York Inc, 1970). 


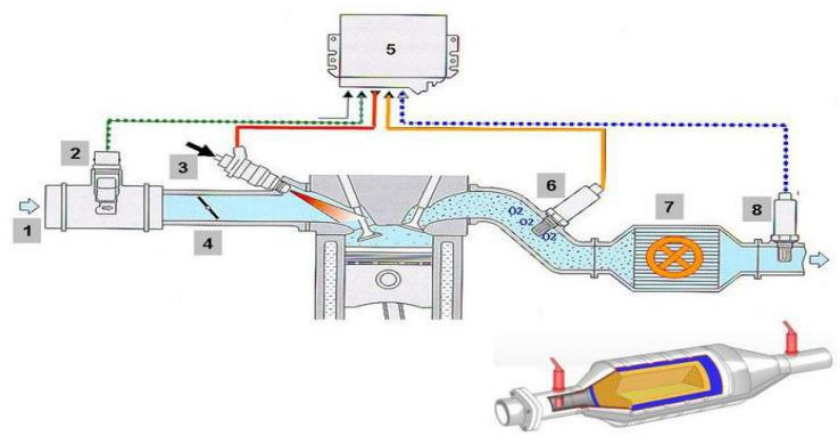

Gambar 2. Letak Catalytic Converter Pada Sistem Kendaraan

Catalytic converter yang umum dipakai ada berbagai macam bentuk, secara garis besar dapat digolongkan menjadi dua golongan (Husselbee W.L., 1985), yaitu: Sistem ini sering disebut juga Sigle bed Oksidation, mampu mengubah $\mathrm{CO}$ dan $\mathrm{HC}$ menjadi $\mathrm{CO} 2$ dan $\mathrm{H} 20$. Catalytic jenis ini beroperasi pada beroperasi pada kendaraan udara berlebih (Excess air setting). Udara berlebih yang digunakan untuk proses oksidasi dapat diperoleh melalui pengaturan campuran miskin (Lean mixture setting) atau system injeksi udara sekunder. Jenis ini banyak digunakan pada motor diesel karena kemampuannya mengoksidasi zat-zat partikel dengan mudah.

Pada system ini terdiri dari dua system katalis yang dipasang segaris. Dimana gas buang pertama kali mengalir melalui Catalytic Reduksi dan kemudian Catalytic Oksidasi. Sistem pertama (bagian depan) merupakan kalatis reduksi yang berfungsi menurunkan emisi NOx, sedang system kedua ( bagian belakang ) merupakan katalis oksida yang menurunkan emisi HC dan CO. Mesin yang dilengkapi dengan system ini biasanya dioperasikan dengan kondisi campuran kaya.

Tipe yang lain adalah Tree-Way Catalytic converter. Pada tipe ini dirancang untuk mengurangi gas-gas polutan seperti $\mathrm{CO}, \mathrm{HC}$ dan Nox yang keluar dari exhaust system dengan cara mengubah melalui reaksi kimia menjadi CO2. Uap air $(\mathrm{H} 2 \mathrm{O})$ dan Nitrogen $(\mathrm{N})($ Emission Control Toyota, 2000).

Penelitian yang dilakukan oleh Dwyer dengan menggunakan skala laboratorium menunjukkan bahwa aktifitas Catalytic Copper Chromite yang merupakan campuran antara $\mathrm{CuO}$ dengan $\mathrm{Cr} 2 \mathrm{O} 3$ lebih baik daripada campuran tunggalnya dalam mengosidasi CO. Disamping itu masih ada logam katalis yang lebih murah, mudah dikerjakan dan mudah didapat untuk dijadikan catalityc converter antara lain : $\mathrm{CuO} /$ zeolite alam, $\mathrm{Cu}-\mathrm{Al} 2 \mathrm{O} 3, \mathrm{Cu}, \mathrm{Mn}, \mathrm{Mg}$ dan Zeolit Alam, Catalytic converter jenis ini mampu mengurangi emisi gas buang ( $\mathrm{CO}, \mathrm{HC}$, Nox) cukup tinggi antara 16\% sampai 80\% (Dwyer, 1973). 


\section{Katalis}

Media katalis adalah suatu zat yang mempercepat laju reaksi kimia pada suhu tertantu, tampa mengalami perubahan atau terpakai oleh reaksi itu sendiri. Media yang biasa digunakan sebagai katalis adalah logam yang mahal dan jarang seperti Palladium, Platinum dan Stainless Steel (Heisler, 1995 ).

Katalis adalah suatu zat yang mempercepat laju reaksi kimia pada suhu tertentu tanpa mengalami perubahan atau terpakai oleh reaksi itu sendiri, suatu katalis berperan dalam reaksi tapi bukan sebagai pereaksi ataupun produk. Katalis memungkinkan reaksi berlangsung lebih cepat atau memungkinkan reaksi pada suhu lebih rendah akibat perubahan yang dipicunya terhadap pereaksi. Katalis menyediakan suatu jalur pilihan dengan energi aktivasi yang lebih rendah sehingga katalis mengurangi energi yang dibutuhkan untuk berlangsungnya reaksi tanpa adanya perubahan pada bahan tersebut ikut bereaksi dalam proses. Selanjutnya pada akhir reaksi akan ditemukan kembali dalam jumlah yang sama seperti saat sebelum reaksi (Rolf, 1992)

\section{Torsi Dan Daya}

Torsi dan daya dari motor bakar yang diperoleh dari hasil pengkonversian energi termal (panas) hasil pembakaran menjadi energi mekanik. Torsi didefinisikan sebagai besarnya momen putar yang terjadi pada poros output mesin akibat adanya pembebanan dengan sejumlah massa $(\mathrm{kg})$, sedangkan daya didefinisikan sebagai besarnya tenaga yang dihasilkan motor tiap satu satuan waktu. Pengukuran torsi dapat dilakukan dengan meletakkan mesin yang akan diukur torsinya pada engine testbed dan poros keluaran dihubungkan dengan rotor dinamometer (Heywood, 1988).

Performa mesin (engine performance) adalah adalah prestasi kinerja suatu mesin, dimana prestasi tersebut erat hubungannya dengan daya mesin yang dihasilkan serta daya guna dari mesin tersebut. Kinerja dari suatu mesin kendaraan umumnya ditunjukkan dalam tiga besaran, yaitu tenaga yang dapat dihasilkan, torsi yang dihasilkan, dan jumlah bahan bakar yang dikonsumsi. Tenaga bersih yang dihasilkan dari poros keluar mesin disebut "brake horse power" (Bhp). Tenaga total yang dapat dihasilkan dari piston mesin disebut "indicated horse power" (Ihp). Sebagian dari indicated horsee power ini hilang akibat gesekan dan energi kelembaban dari massa yang bergerak yang disebut "friction horse power" (Arismunandar, 2002).

Torsi atau momen putar motor adalah gaya dikalikan dengan panjang lengan (Arends\&Berenschot 1980:21), pada motor bakar gaya adalah daya motor sedangkan panjang 
lengan adalah panjang langkah torak. Bila panjang lengan diperpanjang untuk menghasilkan momen yang sama dibutuhkan gaya yang lebih kecil, juga sebaliknya bila jaraknya sama tapi gaya diperbesar maka momen yang dihasilkan akan lebih besar pula. Ini berarti semakin besar tekanan hasil pembakaran di dalam silinder maka akan semakin besar pula momen yang dihasilkan. Torsi maksimum tidak harus dihasilkan pada saat daya maksimum pada saat yang bersamaan. Torsi (momen) sangat erat hubunganya dengan efisiensi volumetrik dari motor itu, artinya momen sangat tergantung pada jumlah bahan bakar yang dapat dihisap masuk kedalam silinder dan kemudian dibakar, karena semakin banyak bahan bakar yang dapat dibakar berarti semakin tinggi atau besar pula gaya yang dihasilkan untuk mendorong torak.

\section{METODELOGI PENELITIAN}

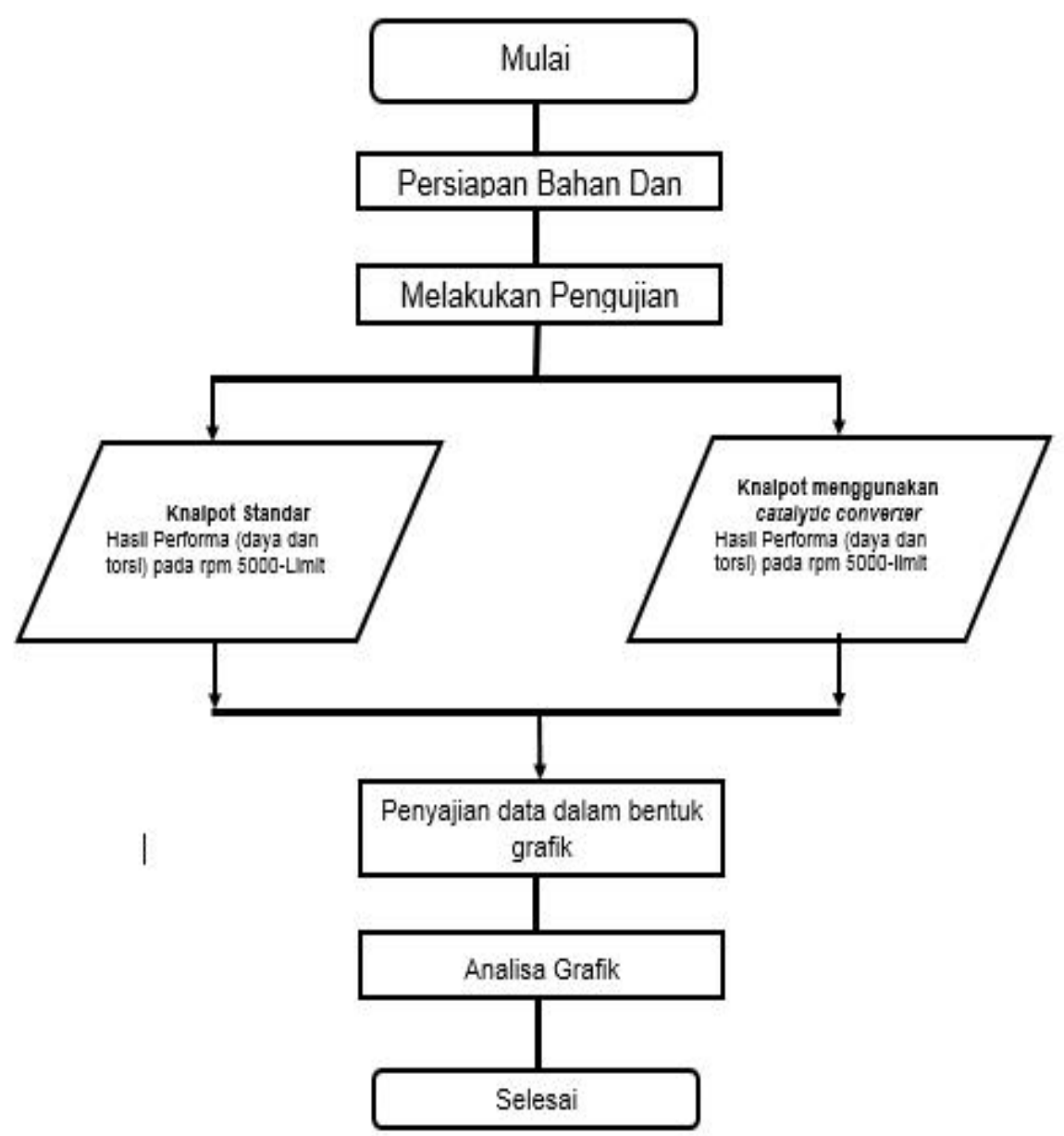

Gambar 3 Flow chart penelitian 


\section{HASIL DAN PEMBAHASAN}

\section{Hasil Pengujian Catalytic converter Terhadap Daya Dan Torsi}

Pengujian menggunakan dynotest dilakukan pada putaran mesin $5000 \mathrm{rpm}$ - limit, dari tabel hasil pengujian dynotest, di dapatkan hasil terbaik dari masing-masing pengujian. Dari hasil pengujian diatas jika dimasukkan kedalam bentuk grafik adalah sebagai berikut:

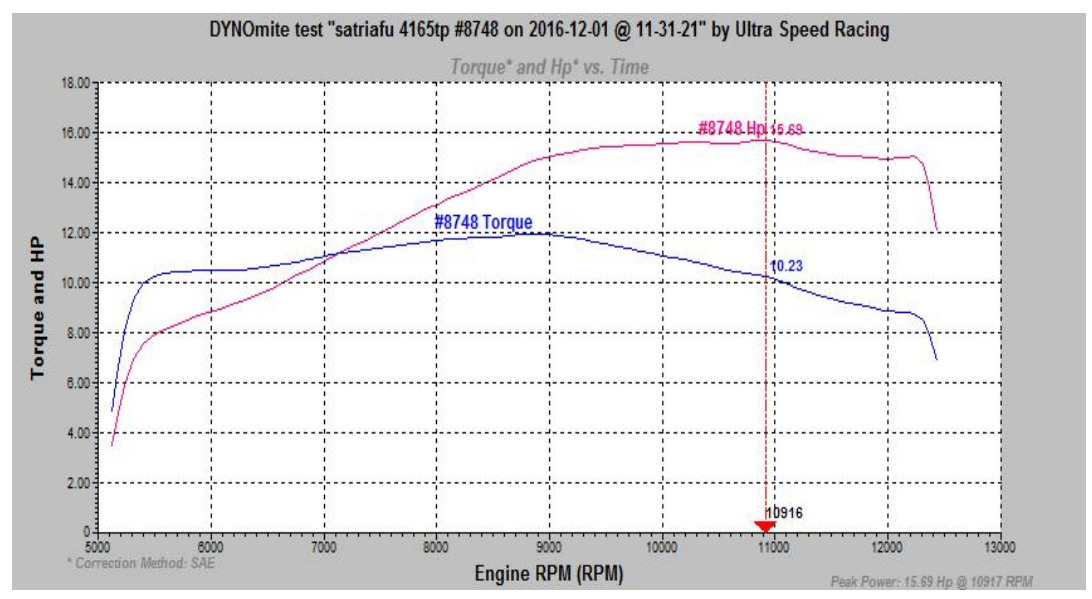

Gambar 4 Grafik Daya Dan Torsi Terhadap rpm tanpa Catalytic converter

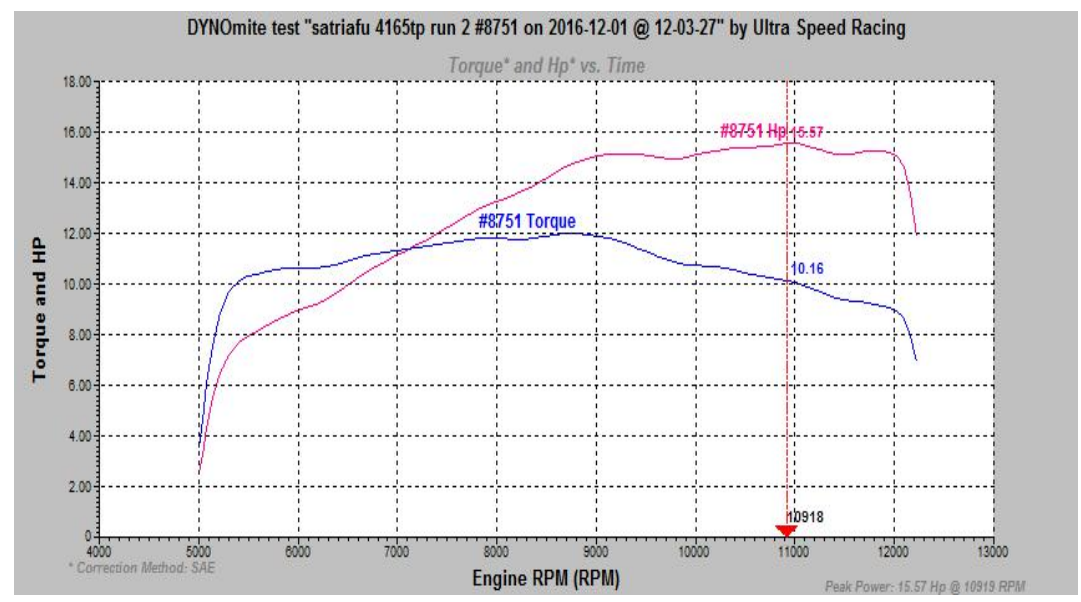

Gambar 5 Grafik Daya Dan Torsi Terhadap rpm bentuk honey comb 


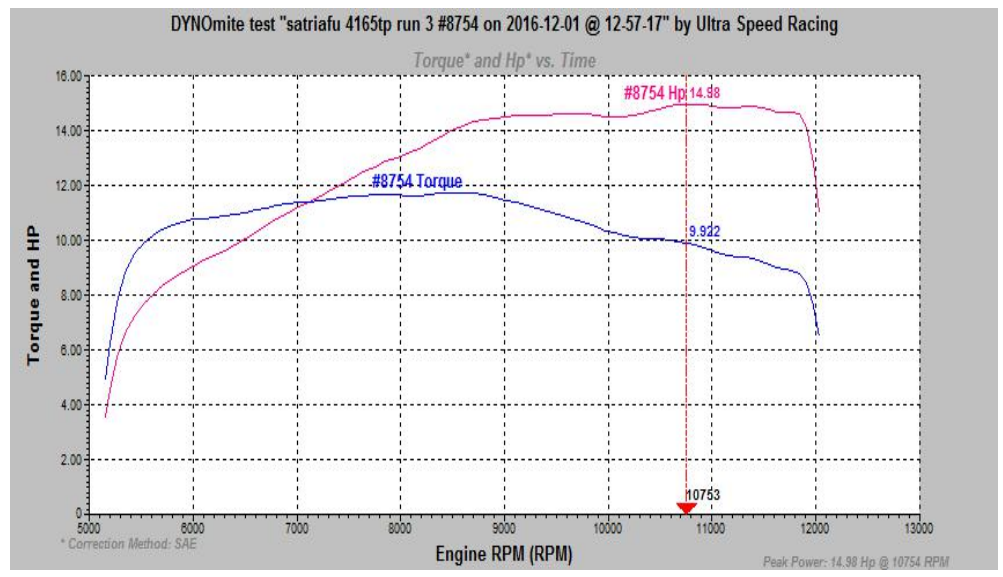

Gambar 4.7 Grafik Daya Dan Torsi Terhadap rpm bentuk plat

Dari ketiga grafik diatas dapat dibandingkan nilai daya dan torsi antara tanpa Catalytic converter, Catalytic converter berbentuk honey comb, dan Catalytic converter berbentuk plat. Jika dimasukkan ke dalam bentuk grafik adalah sebagai berikut.

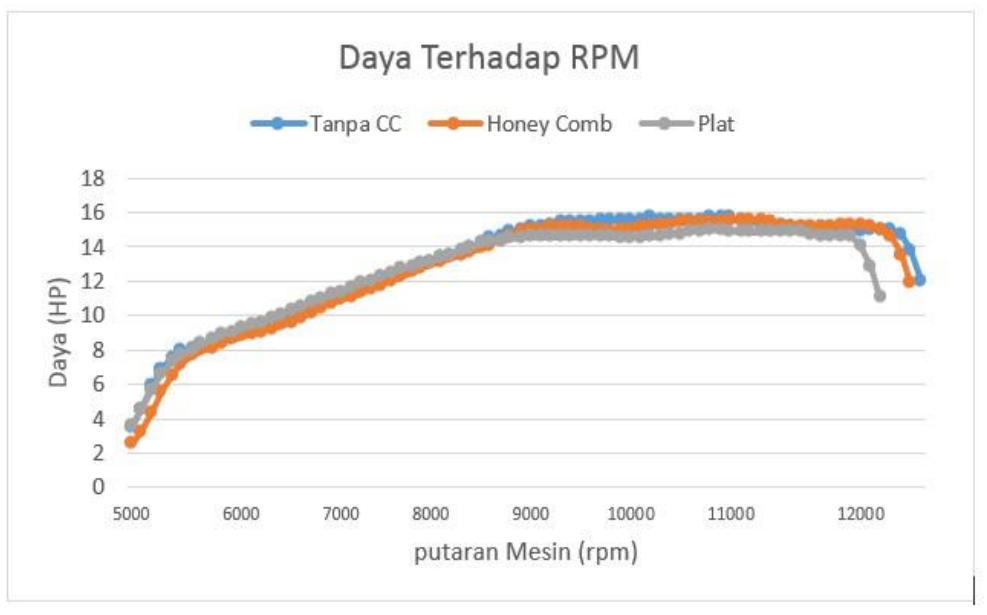

Gambar 6 Grafik daya terhadap rpm

Dari grafik diatas dapat diketahui bahwa daya motor tertinggi terdapat pada knalpot tanpa Catalytic converter dengan 15,69 HP pada 10916 rpm, selanjutnya knalpot dengan Catalytic converter berbentuk honey comb dengan 15,57 HP pada $10918 \mathrm{rpm}$, dan yang terakhir knalpot dengan Catalytic converter berbentuk plat dengan 14,98 HP pada $10753 \mathrm{rpm}$.

Dari data diatas dapat diketahui bahwa penggunaan Catalytic converter pada saluran buang dengan bentuk honey comb hanya mengurangi daya maksimum sebesar 0,12 HP dibandingan 
dengan knalpot tanpa Catalytic converter. Hal ini dikarenakan bentuk Catalytic converter honey comb yang tidak menghalangi secara langsung aliran gas buang sehingga back prees yang dihasilkan dari pemasangan Catalytic converter sangat kecil.

Sedangkan pada knalpot dengan menggunakan Catalytic converter berbentuk plat mengurangi daya maksimum sebesar 0,71 HP dibandingkan dengan knalpot tanpa Catalytic converter. Hal ini dikarenakan bentuk Catalytic converter plat yang menghalangi secara langsung gas buang kendaraan. Sehingga menghasilkan back press yang cukup tinggi yang menyebabkan pada putaran mesin tinggi gas buang pada kendaraan menjadi sedikit terhambat.

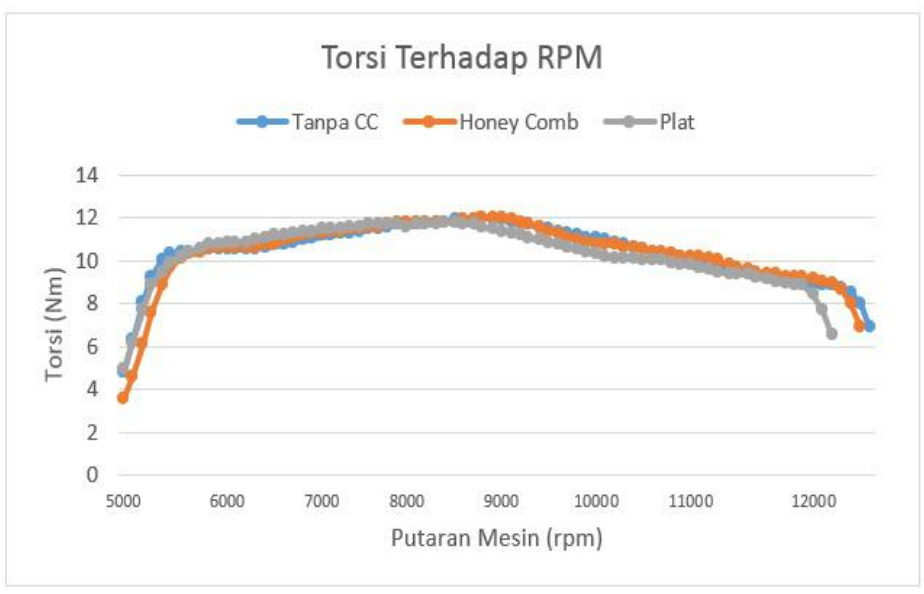

Gambar 7. Grafik Torsi terhadap rpm

Dari grafik diatas dapat diketahui bahwa daya motor tertinggi terdapat pada knalpot Catalytic converter berbentuk honey comb dengan $12 \mathrm{Nm}$ pada putaran mesin $8801 \mathrm{rpm}$, selanjutnya knalpot tanpa Catalytic converter dengan 11,96 Nm pada putaran mesin $8859 \mathrm{rpm}$, dan yang terakhir knalpot dengan Catalytic converter berbentuk plat dengan 11,76 Nm pada putaran mesin $8595 \mathrm{rpm}$.

Dari data diatas dapat diketahui bahwa penggunaan Catalytic converter pada saluran buang dengan bentuk honey comb meningkatkan torsi maksimum sebesar 0,04 $\mathrm{Nm}$ dibandingan dengan knalpot tanpa Catalytic converter. Hal ini dikarenakan bentuk Catalytic converter honey comb yang tidak menghalangi secara langsung aliran gas buang sehingga back prees yang dihasilkan dari pemasangan Catalytic converter sangat kecil.

Sedangkan pada knalpot dengan menggunakan Catalytic converter berbentuk plat mengurangi torsi maksimum sebesar 0,2 Nm dibandingkan dengan knalpot tanpa Catalytic converter. Hal ini dikarenakan bentuk Catalytic converter plat yang menghalangi secara langsung gas buang 
kendaraan. Sehingga pada putaran mesin tinggi gas buang pada kendaraan menjadi sedikit terhambat.

\section{KESIMPULAN}

Berdasarkan hasil pengujian, dapat ditarik beberapa kesimpulan mengenai penggunaan Catalytic converter pada motor Suzuki Satria FU 150 yaitu :

1. Catalytic converter berbentuk honey comb mampu mengimbangi performa dari knalpot tanpa Catalytic converter dapat dilihat dari nilai daya dan torsi maksimumnya, sedangkan Catalytic converter berbentuk plat mengalami penurunan daya dan torsi dibandingkan knalpot tanpa Catalytic converter.

2. Catalytic converter berbentuk honey comb dibandingkan knalpot tanpa Catalytic converter nilai daya maksimum nya hanya menurun $0,12 \mathrm{HP}$, sedangkan nilai torsi maksimumnya meningkat $0,04 \mathrm{Nm}$.

3. Catalytic converter berbentuk plat dibandingkan knalpot tanpa Catalytic converter nilai daya maksimum nya menurun $0,71 \mathrm{HP}$, sedangkan nilai torsi maksimumnya menurun $0,2 \mathrm{Nm}$.

\section{DAFTAR PUSTAKA}

Aditya, Pradana., Ir. Arijanto, MT. 2014. Pengujian Penggunaan Katalisator Broquet Terhadap Emisi Gas Buang Mesin Sepeda Motor 4 Langkah

Dwi, Septian Sulistiyono, 2014. Unjuk Kemampuan Metallic Catalytic converter Berbahan Dasar Kuningan Berlapis Nikel Terhadap Performa Mesin, Reduksi Emisi Gas Buang, Dan Tingkat Kebisingan Sepada Motor Yamaha V-ixion tahun 2011

Irawan, Bagus RM. 2012. Rancang Bangun Catalytic converter Material Substrat Tembaga Berlapis Mangan Untuk Mereduksi Emisi Gas Karbon Monoksida Motor Bensin

Irawan, Bagus RM., Purwanto Dan Hadiyanto. 2014. Unjuk Kemampuan Katalis Tembaga Berlapis Mangan Model 2 Untuk Mengurangi Emisi Gas Carbon Monoksida Motor Bensin (

Kusuma, I Putu Krisna Nara. 2015. Pengaruh Variasi Tekanan Pada Intake Manifold Terhadap Performance Mesin 1500 CC (Skripsi). Bali : Universitas Udayana. 